\title{
Histological and Biometric Study of the Effects of Fusarium Graminarum Silver Nanoparticles on the Kidney in Male Albino Mice
}

\author{
Sahar A. H. AL-Sharqi \\ Assistant Professor / Dep.of Biology, College of Science, Mustansiriyah University, Baghdad/Iraq
}

\begin{abstract}
An approach to synthesizing silver nanoparticles(AgNPs)using a Fusarium graminarum fungus was established in the present study.These nanoparticles are identified with the following techniques to confirm the form, size, and other physical properties of the crystal:UV-Visible Spectroscopy(UV-Vis), where the AgNPs showed absorbance at $420 \mathrm{~nm}$, while X-Ray Diffraction (XRD)showed diffraction peaks at $\left(38.05^{\circ}, 4\right.$ $\mathrm{nm})$. The experiment consisted of 40 mice divided into two groups, the first group of 20 mice was considered to be the control animals and the other group 20mice was 21 day of treatment with a dose of $\mathrm{AgNPs}(0.1 \mathrm{ml} /$ day).Microscopic examination of the kidney section showed lobulated glomeruli,a large area of hemorrhage, changes in degeneration, and inflammatory cell infiltration. Biometric changes of the renal corpuscle showed no significant difference between the study group,while Bowman's capsule,Proximal,and distal convoluted tubules revealed increased significant differences between the two groups.
\end{abstract}

Keywords:Fusarium graminarum, toxicity,AgNPs, kidney,Image $J$

\section{Introduction}

Nanoparticles are defined as very small individual minutes whose dimensions are between 1- 100 nanometers $^{(1)}$, and because of their small size compared to some materials that are more than 100 nanometers in diameter and with a large surface area in relation to their size, different degrees of biological effects, chemical reactions, and highly distinctive properties are not found in the materials. The other, because of its small size, can easily enter the cells of living things ${ }^{(2)}$. Several previously published studies reported that liver and kidneys were target sites for silver deposition ${ }^{(3)}$,after the entry of silver nanoparticles(AgNPs)into human or animal bodies via several ways including inhalation, ingestion, and the skin ${ }^{(4)}$. Also, other studies documented that nanosilver had the capacity to induce toxicity and inflammatory response in these tissues ${ }^{(5,6)}$.

The use of eukaryotic organisms such as Fusarium graminarum and other species has attracted considerable potential for producing large-scale metal nanoparticles because the enzymes that are secreted by the fungi are an essential component for the biosynthesis of metal AgNPs due to their excellent properties and specific characteristics.As well as its therapeutic potential for treating a variety of diseases including acquired immunodeficiency syndrome and retinal neovascularization ${ }^{(7)}$.

The aim of the study is to know the effects of AgNPs from the Fusarium fungi in the kidney of mice in addition to studying their nanoparticles due to the lack of studies around them.

\section{Materials and Method}

\section{Fusarium graminarum isolation}

Isolated from the decayed banana fruit,Fusarium graminarum has been maintained by serial cultivation on potato dextrose agar medium, incubated at $28^{\circ} \mathrm{Cfor}$ 4-5 days,potato dextrose agar was prepared that according to the manufacturer's instructions, $39 \mathrm{gm}$ Potato dextrose agar should be dissolved in $1000 \mathrm{ml}$ distilled water.Sterilized by autoclaving at a pressure of $15 \mathrm{lbs}$ and temperature of $121^{\circ} \mathrm{C}$ for 15 minutes. It was 
cooled to $45-50^{\circ} \mathrm{C}$, and subsequently added antibiotic chloramphenicol(250mg/liter)to the sterile Petri dishes.Isolates of Fusarium graminarum is cultivated. The potato dextrose broth medium was performed by suspending 24 grams of distilled water in 1000 millilitres. Heat up full to remove the medium.Sterilize at a pressure of $15 \mathrm{lbs}$ and temperature $121^{\circ} \mathrm{C}$ in $15 \mathrm{~min}$ by autoclaving.It was cooled down then added antibiotic chloramphenicol( $250 \mathrm{mg} /$ liter $)$. This broth was used in the extracellular synthesis of AgNPs for cultivating Fusarium graminarum.

\section{Preparing Fusarium graminarum AgNPs}

The $250 \mathrm{ml}$ of Fusarium graminarum mycelia was placed in a beaker containing $100 \mathrm{ml}$ of PDB medium and then incubated for 5 days at a temperature of $25 \pm 2^{\circ} \mathrm{C}$. The mycelia were collected and purification with filter paper(No.42)to get rid of any remaining parts of the mycelia and then re-suspended the mycelia in $100 \mathrm{ml}$ of distilled water incubated at $25^{\circ} \mathrm{C}$ for 24 hours.After filtering, the mycelia cells were collected and divided into two parts:

- The first part was treated with a $1 \mathrm{mM}$ solution of silver nitrate(AgNO3)and incubated at room temperature, which changed color to brown and was considered a positive control.

The second part without adding AgNO3 to the filter cells, the color has not changed and is considered a negative control.

The AgNO3 can be observed by changing the color of the fungal filtrate. The concentration, size, aggregation state and crystal morphology were measured using the following techniques:

1) Atomic absorption spectroscopy flame (AASF)

The AASFexamines the concentration of the elements in a liquid sample,depending on the energy absorbed from confident light wavelengths. The silver ion concentration identified in the colloidal solution was $2.5 \mu \mathrm{g} / \mathrm{ml}$, where this concentration was considered stock.

\section{2) UV-Visible spectroscopy}

Ultraviolet visible spectroscopy(UV-VIS)used to investigate the characteristics of nanomaterials involving aggregation state,concentration,size, and even bio-conjugation when the absorption shapes of nanomaterials are distinguished by passing light through a sample and measuring light transmission through a sample.One milliliter of AgNPs was examined on the spectrophotometer system in the chemistry department of the College of Science at Mustansiriyah University ${ }^{(8)}$.

3) X-Ray diffraction (XRD)

$\mathrm{X}$-ray diffraction is an analytical technique primarily used for determining the crystallite size of AgNPs in solution ${ }^{(9)}$.

4) Atomic force microscopy (AFM)

The AFM characterized biosynthesized nanoparticles.On a glass slide a tinny film of the sample was set by dipping $100 \mu \mathrm{l}$ of the sample on the slide, allow to dry for 5 minutes. The slides were scanned with microscopy by Atomic Force ${ }^{(10)}$.

\section{Experimental animals}

The study was conducted using 40 male albino mice obtained from the Iraqi Center for Cancer Research and Medical Genetics Mustansiriyah University and their ages ranged between 8-12 weeks and a weight of 20$28 \mathrm{gm}$.During the experiment, the animals were placed under laboratory conditions of aeration, lighting, and heat.The animals were divided into two groups: the first included 20 mice as a control group, and the second included 20 mice,dosed with $0.1 \mathrm{ml} /$ day for 21 days in Fusarium AgNPs at a concentration of $2.5 \mu \mathrm{g} / \mathrm{ml}$.

\section{Histological and Biometrical study}

The tissue sections were prepared according to Suvaran et al. ${ }^{(11)}$.Kidney samples were fixed with formalin (10\%).After, samples were processed, embedded in paraffin waxed, cut into $5 \mu \mathrm{m}$ thick, and stained with hematoxylin-eosin stain.

Barometric measurements were performed to measure the diameters of the renal corpuscle, Bowman's capsule space and proximal and distal convoluted tubules using an Image J program (Sun microsystems,Inc.USA).

\section{Statistical Analysis}

The statistical analysis was carried out with the software SPSS version 25.0(SPSS Inc.,Chicago, 
IL,USA).The data were expressed as mean \pm standard error(SEM). The means analysis was performed by t-test of independent-samples.A statistically significant value of $\mathrm{P} \leq 0.05$ was found.

\section{Results and Discussion}

\section{Detection of Fusarium AgNPs and UV-Visible spectroscopy}

The synthesis of AgNPs by using Fusarium graminarum was showed after adding $\mathrm{AgNO} 3$ to the filtered cell.The color of the mixture changed from colorless to dark -brown compared with negative control remain colorless,fig.(1a)illustrated the changes in color which indicated the presence of Fusarium graminarum AgNPs.These results corresponding with $^{(12)}$,reported the appearance of brown was a clear indicator of the synthesis of AgNPs in the reaction combination.

On the other hand,Fusarium AgNPs properties by UV-Visible spectroscopy techniqueconfirms the presence of Fusarium AgNPs by measuring the absorbance of the bio-reduced solution at wavelengths between 300 and $800 \mathrm{~nm}$.Extinction spectrophotometer of UV and visible Vis light (UV-Vis spectrum)confirmation of the presence of Fusarium AgNPs is permitted because of a distinctive Plasmon resonance,which showed a peak absorption at $420 \mathrm{~nm}$, fig.(1b).

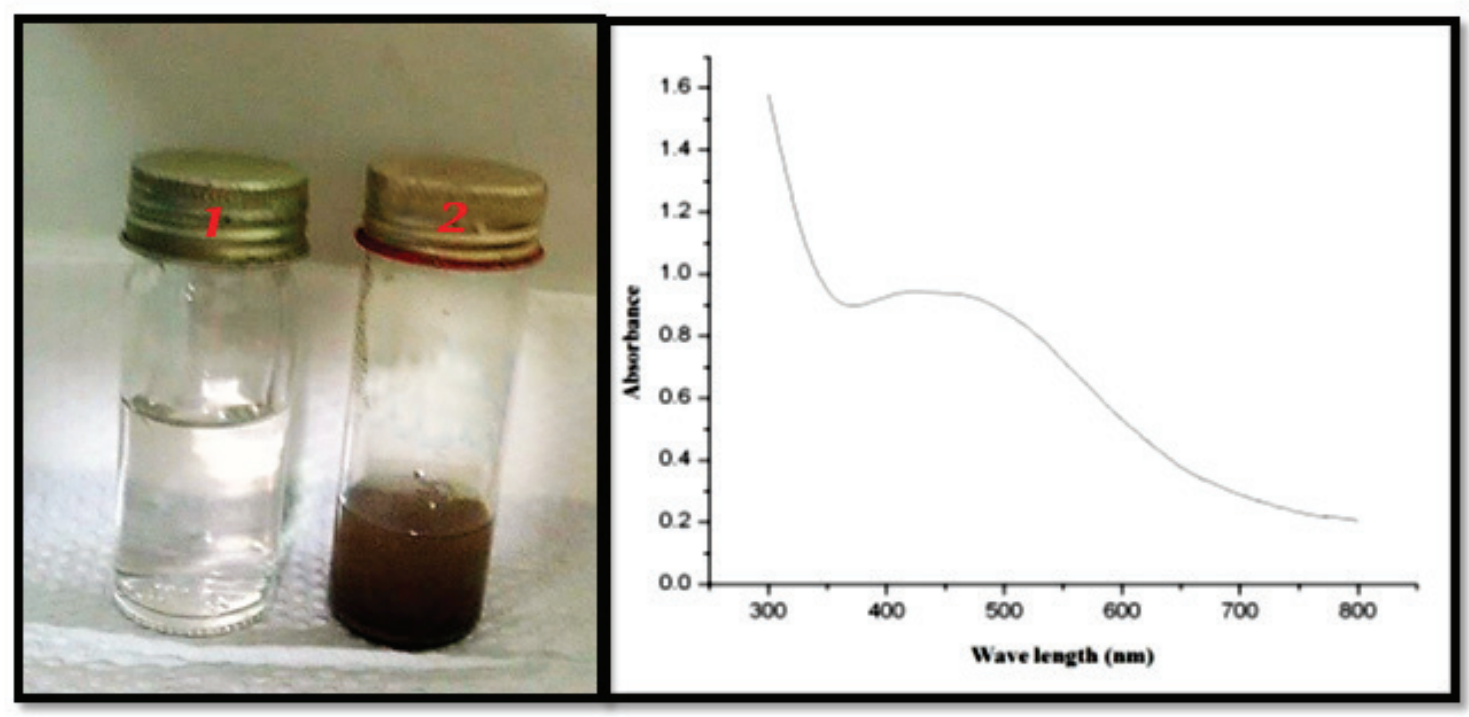

Figure(1):(a)Synthesis of AgNPs:(1)negative control observed colorless,(2)synthesized Fusarium graminarum AgNPs showed brown color.(b)UV-Visible spectroscopy of Fusarium AgNPs

The results corroborate those of previous studies such as Birla et al. ${ }^{(13)}$ who showed that the absorption peak is about $420 \mathrm{~nm}$,which is specific to AgNPs. There was one peak refers to the synthesis of spherical nanoparticles, and it is known that there is a very close relationship between the absorption spectra of UVVis and the size and shape of AgNPs.Also,Singh et $a l .{ }^{(14)}$ reported that the production of AgNPs by using endophyte fungus Fusarium spp.with maximum surface Plasmon resonance peak at 420 nm.Ingle et al. ${ }^{(15)}$ reported that the UV spectrum is allowed to confirm the existence of metal nanoparticles due to distinctive Plasmon resonance.

Fusarium graminarum AgNPs characterized by XRD

The XRD pattern of Fusarium AgNPs as revealed in fig.(2),the diffraction peaks at $38.05^{\circ}, 44.22^{\circ}, 64.32$ and $77.31^{\circ}$ were correspondent to the $(111,200,220,311)$ the faces of the face-centered crystal cube structure,therefore the average crystallite size was $28.225 \mathrm{~nm}$. 
The results correspond to the results of Shafiq et $a l .{ }^{(16)}$ who revealed that the XRD diffraction measured in AgNPs resulted in four intense peaks and this further confirms that AgNPs made in extracellular filtration is present in the form of AgNPs.Also,Mahmoud et $a l .^{(12)}$ reported four distinct diffraction peaks at angles $38.15^{\circ}, 44.18^{\circ}, 64.63^{\circ}$, and $77.50^{\circ}$ correspond to(111,200,220 and 311)planes of the face-centered cubic.This further asserts that the AgNPs formed in extracellular filtration is present in the form of AgNPs. Also,similar results have been reported by Gholami et al. ${ }^{(17)}$ when extracted nanoparticles from Fusarium oxysporum.

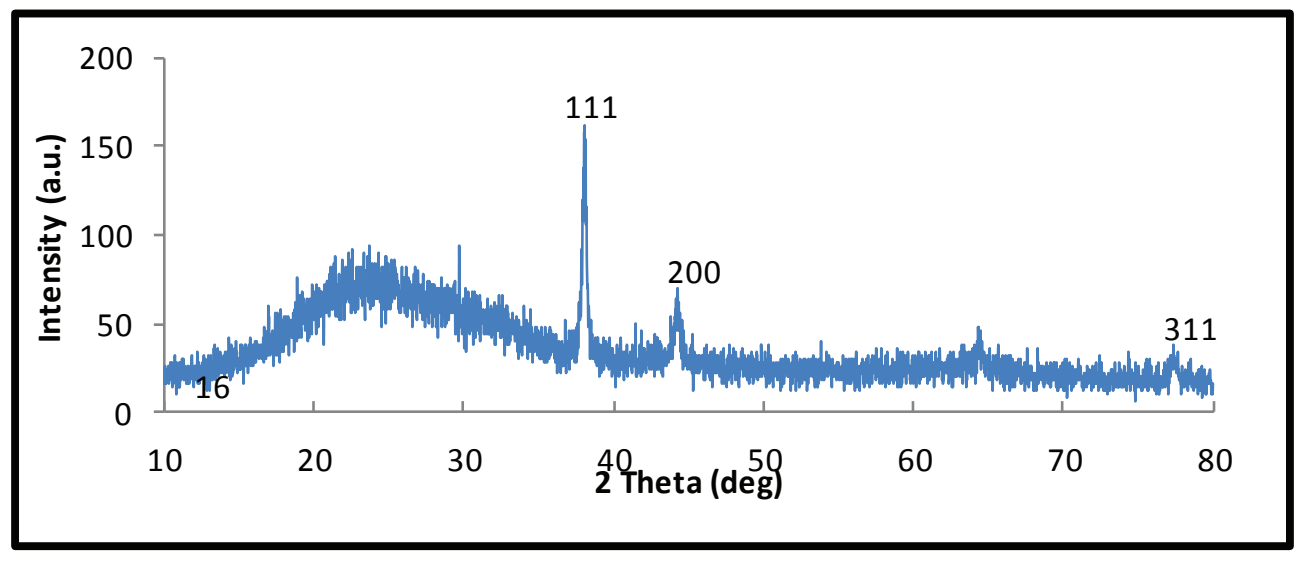

Figure(2):X-Ray pattern of Fusarium AgNPs

\section{Fusarium graminarum AgNPs characterized by AFM}

Determine of Fusarium AgNPs surface morphology and sizes were measured, using the AFM. The images of AFM for Fusarium AgNPs in figure(3a)represented particle size distribution, where the average diameter is $94 \mathrm{~nm}$.
While in fig.(3 b, c)showed AFM picture in two dimensions(2D)and three dimensions(3D), it explains structural shape for grains, found that the average roughness is $9.33 \mathrm{~nm}$ and Root mean square is $11.6 \mathrm{~nm}$. The AFM is a very good technique for measuring surface morphology and fine structure of nanoparticles ${ }^{(18)}$. The AFM topology is very helpful in revealing the exact size and shape of $\operatorname{AgNPs}^{(19)}$.

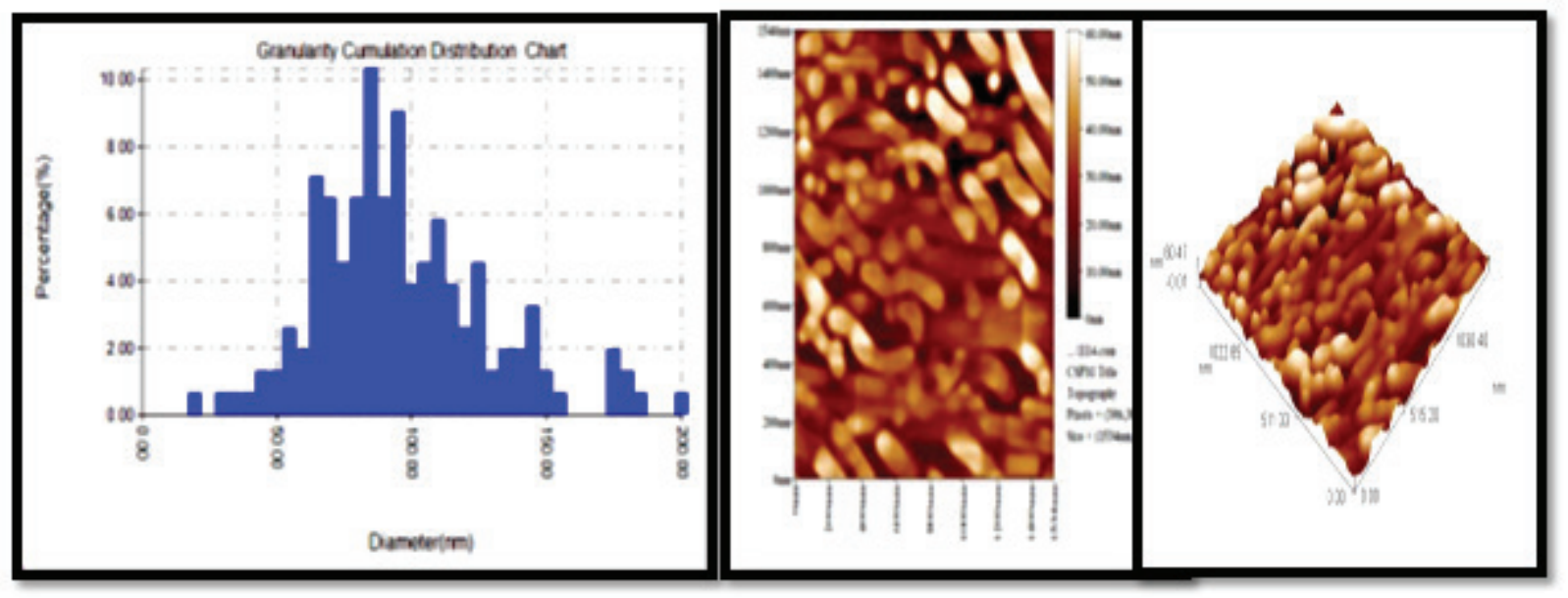

Figure(3):(a)Granularity volume distribution of Fusarium AgNPs.(b)AFM images of Fusarium AgNPs with two dimensions 2D,(c)three dimensions 3D. 


\section{Histological study of kidney}

Sample of control of kidney tissue demonstrated a normal histological structure of the convoluted tubules and renal corpuscles fig.(4a).In treated mice with Fusarium AgNPs after 21 day showed dilation in the collecting tubule fig.(4b),while, dilation in the renal corpuscle with hemorrhage in the interstitial space between the tubules fig.(4c).Also,hydropic degeneration in epithelium cells of the renal tubules with hemorrhage in the interstitial space between the renal tubules fig. (4d).

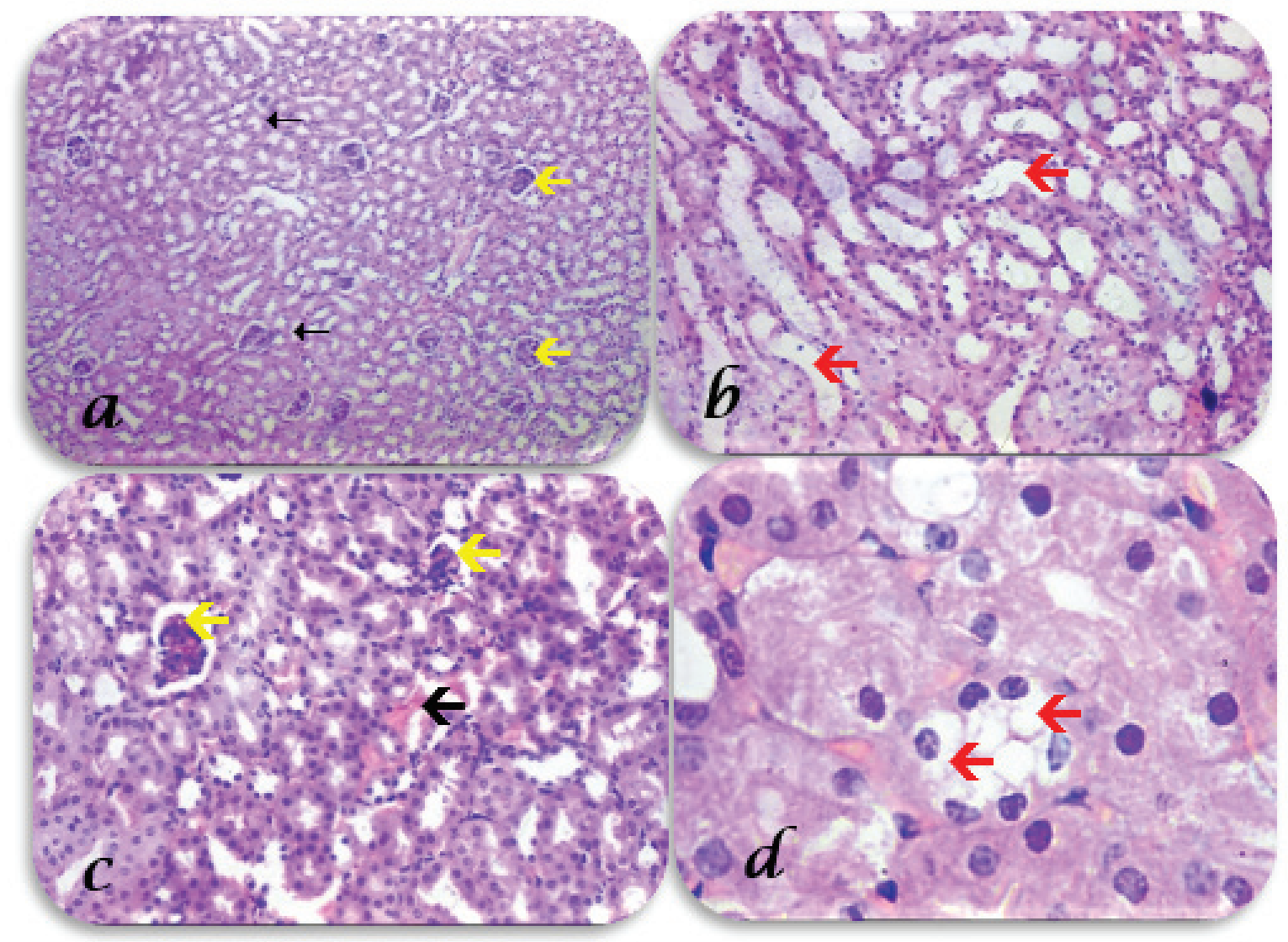

Figure(4):Cross section of the Fusarium AgNPs effects after 21 day in kidney of mice detected by H\&E staining:A.control group shows normal appearance of the convoluted tubules (black arrows)renal corpuscles (yellow arrows)(X4).B:dilation in the collecting tubule(red arrows)(X10), C:dilation in the renal corpuscle(yellow arrow)hemorrhage in the interstitial space between the tubules(black arrow)(X10),D:hydropic degeneration in epithelium cells of the renal tubules(yellow arrow)(X40).

In the current study, the kidney tissue showed a clear effect, represented by degenerative changes in the epithelial cells lining the renal tubules when treated with Fusarium AgNPs after 21day.This may be due to the accumulation of AgNPs in the renal tubules, which may have led to a change in the permeability of the cell wall due to its effect on the entry and exit of ions into the cells of the renal tubules ${ }^{(20,21)}$.Also, may be that most of the AgNPs is caused the renal artery damage which indicates to the detoxifying organ ${ }^{(22)}$. The toxicity of silver ions has led in a number of studies that release of silver ions $(\mathrm{Ag}+)$ from AgNPs could be responsible for toxic responses seen in exposures to $\operatorname{AgNPs}^{(23)}$.Although there are not a mechanism of action for toxic histological changes after AgNPs treatment; but previous study hypotheses that silver nanoparticles can disrupts the, $\mathrm{Cl}-, \mathrm{H}+$ and $\mathrm{Na}+$ exchanges at the cell membrane ${ }^{(24)}$.Other researcher proposed that exposure to AgNPs involved genes in inflammation and dissolved Ag implicate oxidative stress,study by Vasanth and Kurian ${ }^{(25)}$ reported collected evidence suggests that the kidney is one of the major organs with reported adverse 
effects of nanoparticles and the accumulation of NPs in the kidney,leading to nephric inflammation, dysfunction and cell necrosis.Another research by Ma et al. ${ }^{(26)}$ found that the AgNPs disrupt the energy metabolism and cause mitochondria and cell membrane damage in the rat kidney,which can lead to nephrotoxicity caused by AgNPs.

\section{Biometric study of kidney}

Table(1)shows the results of Renal corpuscle,Bowman's capsule,Proximal convoluted tubules, and Distal convoluted tubules diameter respectively in the control group compared with the Fusarium AgNPs group.Non-significant different $(\mathrm{P}<0.05)$ is found in Renal corpuscle diameter of Fusarium AgNPs group $(68.54 \pm 1.39 \mu \mathrm{m})$ compared to that of the control group $(70.45 \pm 0.66 \mu \mathrm{m})$.

Statistically increased significant difference is found in Bowman's capsule diameter between Fusarium AgNPs group(15.96 $\pm 0.34 \mu \mathrm{m})$ as compared with the control group $(8.04 \pm 0.13 \mu \mathrm{m})$. The expansion of Bowman's capsule may be due to the contraction of the glomeruli of the renal glomeruli or to the destruction of the Bowman's visceral layer ${ }^{(27)}$.Roda et al. ${ }^{(28)}$ were evaluated to examine renal responses 28 days after a low AgNPs dose,the AgNPs caused dilatation of the intercapillary and peripheral Bowman's space was showed, as well as with glomerular shrinkage.

On the other hand, increased significant difference is found in Proximal and distal convoluted tubules diameter between Fusarium AgNPs group $(41.38 \pm 0.26,41.66 \pm 0.42 \mu \mathrm{m})$ as compared with the control group $(37.82 \pm 0.60,37.22 \pm 0.33 \mu \mathrm{m})$ respectively. The appearance of glomerular atrophy and disruption in renal tubules is consistent with Sardari et al. ${ }^{(29)}$ which pointed when exposed to AgNPs showed damages in the epithelial lining of renal tubules leading to increased glomerular pressure.Furthermore, study of Meyer ${ }^{(30)}$ revealed that glomerular atrophy might occur to decreased the filtration process in response to damaged tubules, which caused by heavy metals. Another study by Tiwari et al. ${ }^{(31)}$ point out that exposed to AgNPs could be affected due to damaged brush border of epithelial lining of Proximal convoluted tubules.

Table(1): Biomatric changes of renal corpuscle, Bowman's capsule, Proximal and distal convoluted tubules

\begin{tabular}{|l|l|l|l|}
\hline Diameter $/ \boldsymbol{\mu m}$ & $\begin{array}{l}\text { Control group } \\
\mathbf{n}=\mathbf{2 0}\end{array}$ & $\begin{array}{l}\text { Fusarium AgNPs group } \\
\mathbf{n = 2 0}\end{array}$ & P-Value \\
\hline Renal corpuscle & $70.45 \pm 0.66$ & $68.54 \pm 1.39$ & $0.24(\mathrm{NS})$ \\
\hline Bowman's capsule & $8.04 \pm 0.13$ & $15.96 \pm 0.34 *$ & 0.00 \\
\hline Proximal convoluted tubules & $37.82 \pm 0.60$ & $41.38 \pm 0.26^{*}$ & 0.00 \\
\hline Distal convoluted tubules & $37.22 \pm 0.33$ & $41.66 \pm 0.42 *$ & 0.00 \\
\hline *signification differences between group(p<0.05).NS:no signification & & \\
\hline
\end{tabular}

\section{Conclusion}

Our study concluded that because of its ability to enter and translocate within the cell, the size of the AgNPs varies with its toxics effects on the cell and the cell organelles. Therefore, it could be assumed that all nanoparticles are toxic and most likely only free nanoparticles that can penetrate small organelles like mitochondria may trigger adverse health effects. Hence, the AgNPs Fusarium. 
Ethical Clearance: The Research Ethical Committee at scientific research by ethical approval of both MOH and MOHSER in Iraq

\section{Conflict of Interest: Non}

Funding: Self-funding

\section{References}

1. Nikalje AP.Nanotechnology and its applications in medicine. Med Chem.2015;5:081-089.

2. Chen Z,Meng H,Xing G,Chen C,Zhao Y,Jia G,Wang T,Yuan H,Ye C,Zhao F,Chai Z,Zhu C,Fang X,Ma B and Wan L.Acute toxicological effects of copper nanoparticales in vivo.Toxicol. Lett.2006;163(2):109-120.

3. Park E,Bae E,Yi J,Kim Y and Choi K.Repeateddose toxicity and inflammatory responses in mice by oral administration of silver nanoparticles.Environmental toxicology and pharmacology.2010;30(2):162-8.

4. Cameron S,Hosseinian F and Willmore W.A current overview of the biological and cellular effects of nanosilver.International journal of molecular sciences.2018;19(7):2030.

5. Foldbjerg $\mathrm{R}$ and Autrup H. Mechanisms of silver nanoparticles toxicity.Arch Basic Appl Med.2013;1(1):5-15.

6. Gherkhbolagh MH,Alizadeh Z,Asari MJ,Sohrabi M. In vivo induced nephrotoxicity of silver nanoparticles in rat after oral administration. Journal of research in medical and dental science.2018;6(1):43-51.

7. Sriram,MI,Kanth SB,Kalishwaralal $\mathrm{K}$ and Gurunathan S.Antitumor activity of silver nanoparticles in Dalton's lymphoma ascites tumor model. International journal of nanomedicine.2010;5:753-762.

8. Ba-Abbad MM,Kadhum AA,Mohamad AB,Takriff MS and Sopian K.Synthesis and catalytic activity of $\mathrm{TiO} 2$ nanoparticles for photochemical oxidation of concentrated chlorophenols under direct solar radiation. International Journal of electrochemical science.2012;7:4871-4888.

9. Cullity BD.Elements of X-ray Diffraction. 2nd Edition Addison Wesley. London.1978:531.

10. Hemath Naveen KS, Kumar G, Karthik, L and Bhaskara Rao KV.Extracellular biosynthesis of silver nanoparticles using the filamentous fungus Penicillium spp. Archives of applied science Research.2010; 2(6):161-167.

11. Suvaran SK,Layton C and Bancroft JD. Theory and practice of histological techniques. Seventh edition, Churchill livingstone Elsevier.2013.

12. Mahmoud MA,Al-Sohaibani SA,Al-Othman MR,Abd El-Aziz AM and Eifan SA. Synthesis of extracellular silver nanoparticles using Fusarium semitectum (KSU-4) isolated from Saudi Arabia. Digest Journal of Nanomaterials and Biostructures.2013;8(2):589-96.

13. Birla SS, Gaikwad SC, Gade AK and Rai MK. Rapid synthesis of silver nanoparticles from Fusarium oxysporum by optimizing physicocultural conditions.The Scientific World Journal.2013:12.

14. Singh AK, Rathod V,Singh D,Ninganagouda S,Kulkarni P,Mathew J and Haq MU.Bioactive silver nanoparticles from endophytic fungus Fusarium sp. isolated from an ethanomedicinal plant Withania somnifera (Ashwagandha) and its antibacterial activity.International Journal of Nanomaterials and Biostructures.2015;5(1):15-19.

15. Ingle $A$, Gade $A$, Pierrat $S$, Sonnichsen $C$ and Rai M.Mycosynthesis of silver nanoparticles using the fungus Fusarium acuminatum and its activity against some human pathogenic bacteria.Current Nanoscience,2008;4(2):141-144.

16. Shafiq SA,Al-Shammari RH and Majeed HZ.Study of Biosynthesis silver nanoparticles by Fusarium graminaerum and test their antimicrobial activity. International Journal of Innovation and Applied Studies.2016;15(1):43.

17. Gholami-Shabani M,Akbarzadeh A,Norouzian D,Amini A,Gholami-Shabani Z,Imani A,Chiani M,Riazi G,Shams-Ghahfarokhi M and RazzaghiAbyaneh M.Antimicrobial activity and physical characterization of silver nanoparticles green synthesized using nitrate reductase from Fusarium oxysporum. Applied biochemistry and biotechnology.2014;172(8):4084-4098.

18. Verma VC,Kharwar $\mathrm{RN}$ and Gange AC.Biosynthesis of antimicrobial silver nanoparticles by the endophytic fungus Aspergillus clavatus. Nanomedicine.2010;5(1): 33-40.

19. Vijayan S,Koilaparambil D,George TK and Manakulam Shaikmoideen J.Antibacterial and Cytotoxicity Studies of Silver Nanoparticles 
Synthesized by Endophytic Fusarium solani Isolated from Withania somnifera(L.).Journal of Water and Environmental Nanotechnology.2016;1(2):91-103.

20. Mescher AL,Junqueira LC. Junqueiras basic histology:text and atlas.Megraw-hill.2013.

21. Guo H,Zhang J,Boudreau M,Meng J,Yin JJ,Liu $\mathrm{J}$ and $\mathrm{Xu}$ H.Intravenous administration of silver nanoparticles causes organ toxicity through intracellular ROS-related loss of inter-endothelial junction.Part Fibre Toxicol.2016;13:21.

22. Jime 'nez-Lamana J,Francisco L,Eduardo B,Isabel A,Juan R,Juliusz B,Man H,Katarzyna B, Sandra M,Laurent O,Sylvie G,Jean-Max R and Joanna S.An insight into silver nanoparticles bioavailability in rats.Metallomics.2014;6:2242-2249.

23. Korani M,Rezayat SM,Arbabi Bidgoli S.Subchronic dermal toxicity of silver nanoparticles in Guinea pig: special emphasis to heart, bone and kidney toxicities. Iran J Pharm Res.2013;12:511519.

24. Milic M,Leitinger G,Pavicic I,Avdi_cevi_c MZ,Dobrovi_c S,Goessler W,Vr_cek IV. Cellular uptake and toxicity effects of silver nanoparticles in mammalian kidney cells.J Appl Toxicol.2014;35:581-592.

25. Vasanth SB,Gino A and Kurian GA.Toxicity evaluation of silver nanoparticles synthesized by chemical and green route in different experimental
models.Artificial Cells, Nanomedicine, and Biotechnology.2017;45(8):1721-1727.

26. Ma W,Jing L,Valladares A and Bang JJ.Silver nanoparticle exposure induced mitochondrial stress, caspase- 3 activation and cell death: amelioration by sodium selenite.Int J Biol Sci.2015;11:860-867.

27. Alzerjawe BS.Histological changes and functional study of the effect of zinc oxide nanoparticles on the kidney of male albino mice.A thesis of MSc in biology,University of Baghdad.2019.

28. Roda E,Sergio B,Aldo M,Isabella D,Graziano $\mathrm{C}$ and Teresa C. Single Silver Nanoparticle Instillation Induced Early and Persisting Moderate Cortical Damage in Rat Kidneys.Int. J. Mol. Sci.2017;18:2115.

29. Sardari RR,Zarchi SR,Talebi A,Nasri S,Imani S,Khoradmehr A and Sheshde SA.Toxicological effects of silver nanoparticles in rats.African Journal of Microbiology research.2012;6(27):5587.

30. Meyer TW.Tubular injury in glomerular disease. Kidney international.2003;63(2):774-87.

31. Tiwari R,Singh RD,Khan H,Gangopadhyay S,Mittal S,Singh V,Arjaria N,Shankar J,Roy SK,Singh D and Srivastava V.Oral subchronic exposure to silver nanoparticles causes renal damage through apoptotic impairment and necrotic cell death.Nanotoxicology.2017;11(5):671-86. 